\title{
Supercritical Fluid Extraction as a Technique to Obtain Essential Oil from Rosmarinus officinalis $\mathrm{L}$.
}

\author{
GOLCHEHREH KHALILI' ${ }^{1}$ ALI MAZLOOMIFAR ${ }^{2 *}$, KAMBIZ LARIJANI', \\ MOHAMMAD SABERTEHRANI ${ }^{1}$ and PARVIZ ABEROOMAND AZAR ${ }^{1}$
}

\author{
'Department of Chemistry, Science and Research Branch, Islamic Azad University, Tehran, Iran. \\ ${ }^{2}$ Department of Chemistry, Yadegar-e-Imam Khomeini (RAH) Branch, Islamic Azad University, \\ Tehran, Iran. \\ *Corresponding author E-mail: mazloomifar@yahoo.com
}

http://dx.doi.org/10.13005/ojc/330549

(Received: July 19, 2017; Accepted: August 15, 2017)

\begin{abstract}
The aim of this study was the comparison of essential oil of one herb from lamiaceae family namely Rosemary, via supercritical fluid extraction (SFE) and hydrodistillation (HD). The essential oils were analyzed by gas chromatography-quadrupole mass spectrometry (GC-MS). The compounds identified in higher relative abundance were, $\alpha$-pinene (HD: $30.42 \%$, SFE: $0.47 \%$ ), 1,8cineole (HD: $15.46 \%$, SFE: $25.05 \%$ ), Verbenone (HD: 13.09\%, SFE: 5.17\%), Camphor (HD: $8.97 \%$, SFE:15.69\%), Borneol (HD: 7.16\%, SFE: 9.15\%) and $\beta$ э- Caryophyllene (SFE: 6.85\%).
\end{abstract}

Keywords: Rosemary,Supercritical fluid extraction, Hydrodistillation, Essential oil

\section{INTRODUCTION}

Rosemary (Rosmarinus officinalis L.) is a Long-lasting evergreen herb that belongs to the Lamiaceae family ${ }^{1}$. Rosemary is native to the Mediterranean region. It possesses needle-like leaves which contain a powerful fragrance ${ }^{2}$. It is used as a food flavoring agent, and well known medicinally for its powerful antitumor, antibacterial, antifungal and antioxidant activity ${ }^{3-7}$. Rosemary essential oil composition and the ratio between different oil constituents plays a role in its bioactivity ${ }^{8}$. Rosemary oil composition depends on various environmental and genetic factors, as well as on postharvest processing factors ${ }^{9}$. Supercritical fluid extraction showed extremely higher selectivity compared to the conventional techniques
tested.Supercritical fluid extraction is an innovative, clean and environmental friendly technology with particular interest for the extraction of essential oil from plants and herbs. Furthermore, supercritical extracts were often recognized of superior quality when compared with those produced by hydrodistillation ${ }^{10-11}$. The advances that supercritical technology is reaching in the past years are related to the continuous increase of activities connected to scientific research and technological development, which focus on inserting novel processes in the food, pharmaceutical, chemical and cosmetics industries ${ }^{11}$.In this paper, we present a comparative study of the ability of two different techniques to extract the essential oils from Rosmarinus leaves to find the most advantageous in term of essential oil quantity and quality. 


\section{MATERIALS AND METHODS}

\section{Materials}

HPLC grade $n$-hexane and analytical grade anhydrous sodium sulfate were purchased from Merck (Darmstadt, Germany). Dichloromethane was purchased from Aldrich. Carbon dioxide $(99.8 \%$ purity) contained in a cylinder was purchased from Sabalan Co. (Tehran, Iran). The Rosemary (Rosmarinus officinalis L.) leaves used was collected from the north of Tehran, Iran in August 2016.

\section{GC-MS analysis}

The Analyses were performed using a GCMS system (Hewlett-Packard 6890 gas chromatograph coupled to a 5973A mass spectrometer), equipped with split/splitless injector in the splitless mode and at $250^{\circ} \mathrm{C}$ during the chromatographic run. The volatile compounds were separated in a capillary column $(30 \mathrm{~m} \times 0.25 \mathrm{~mm}$, $0.25 \mu \mathrm{m}$ film thickness, HP-5MS) using $\mathrm{N}_{2}$ (99.99 $\%)$ as a carrier gas at a $1 \mathrm{ml} / \mathrm{min}$ flow rate. The oven temperature was varied as follows: $60^{\circ} \mathrm{C}(5 \mathrm{~min})$, then warmed to $250^{\circ} \mathrm{C}$ at $5^{\circ} \mathrm{C} / \mathrm{min}$. then held $10 \mathrm{~min}$. at $250^{\circ} \mathrm{C}$. The mass detector conditions were: transfer line temperature of $220^{\circ} \mathrm{C}$, ion source temperature of $220^{\circ} \mathrm{C}$ and ionization mode with electron impact at $70 \mathrm{eV}$. The Kovats retention index (RI) values were calculated using a homologous series of $n$-alkanes $\left(\mathrm{C}_{8}-\mathrm{C}_{25}\right)$ and values were compared with values reported in the literature and available Adams data ${ }^{12}$. All mass spectra were also compared with the data system library (Wiley 275). Identification of volatile compounds was achieved by matching mass spectra and retention indices (RI) with those obtained from Wiley library as well as from literature data.

\section{Hydrodistillation (HD)}

Rosemary leaves were shade dried at room temperature for 72 hours. The dried rosemary leaves were loaded to hydrodistillation using a Clevenger-type apparatus, according to European Pharmacopeia, and extracted with $1 \mathrm{I}$ of water for $240 \mathrm{~min}$. (until no more essential oil was reused).

\section{Supercritical fluid extraction (SFE)}

A Suprex MPS/225 system (Pittsburgh, $\mathrm{PA}$ ) in the SFE mode was used for all the extractions.
The extraction vessel was a $10 \mathrm{ml}$ stainless steel vessel. Supercritical fluid extractions were conducted at pressure $30 \mathrm{MPa}$ and temperature $40^{\circ} \mathrm{C}$ for a duration of $20 \mathrm{~min}$. static, followed by $35 \mathrm{~min}$. dynamic. These optimized conditions were obtained from literature ${ }^{13} . A$ Duraflow manual variable restrictor (Suprex) was used in the SFE system to collect the extracted essential oil. In order to prevent sample plugging, the restrict point was warmed electrically. The supercritical $\mathrm{CO}_{2}$ flow rate through the Duraflow restrictor was approximately 0.3-0.4 ml/min. (compressed). Plant powder $(3.0 \mathrm{~g})$ was well mixed with $2 \mathrm{~mm}$ diameter glass beads, and was then charged into the $10 \mathrm{ml}$ extraction vessel. The essential oil was extracted from the plant using supercritical $\mathrm{CO}_{2}$. The extracted essential oil was collected in dichloromethane in a $5.0 \mathrm{ml}$ volumetric flask. The final volume of the extract was adjusted to $5.0 \mathrm{ml}$ with dichloromethane at the end ofthe extraction.Four milliliters of solution were poured into a $20 \mathrm{ml}$ beaker. The solvent was evaporated by Bubbling argon gas through the solution. Then the weight of essential oil was measured and the extraction yield was calculated.

\section{RESULT AND DISCUSSION}

The identified constituents in the extracted essential oils from both methods are present in Table1. For hydrodistillation and supercritical fluid extraction 29 and 16 compounds, respectively were characterized, according to $99.91 \%$ and $91.75 \%$ of the essential oils. In the hydrodistillation technique, the essential oil consists of oxygenated compounds $56.33 \%$ and $42.39 \%$ monoterpene hydrocarbons with, $\alpha$-pinene $(30.42 \%)$, 1,8-cineole $(15.46 \%)$, Verbenone (13.09\%), Camphor (8.97\%) and Borneol $(7.16 \%)$ as the major components in the oil.

Comparatively, the main constituents of the oil in supercritical fluid extraction technique were $\alpha$-pinene (0.47\%), 1,8-cineole $(20.05 \%)$, Verbenone $(5.17 \%)$, Camphor (15.69\%),Borneol $(9.15 \%)$ and $\beta$ Caryophyllene $(6.85 \%)$. Furthermore, the oil consists of $76 \%$ oxygenated compounds and $1.39 \%$ monoterpene hydrocarbons.

Fig. 1 shows the major compounds in Rosmarinus officinalis I. essential oil extracted by hydrodistillation and supercritical fluid extraction, it 
was noticed thata large amount of $\alpha$-Pinenewas present in the essential oil via hydrodistillation.

Additionally, higher levels of oxygenated compounds and lower levels of monoterpene hydrocarbons were found in the essential oil extracted by supercritical fluid extraction (Fig. 2).The selectivity of supercritical fluid extraction technique allowed to increase the quantities of oxygenated compounds.

Table.1 :Chemical composition of the essential oil isolated from Iranian Rosmarinus officinalis via hydrodistillation (HD) and supercritical fluid extraction (SFE)

\begin{tabular}{|c|c|c|c|c|}
\hline Compounds & Formula & $\mathbf{R I}$ & $\mathrm{HD}(\%)$ & SFE(\%) \\
\hline$\alpha$-Pinene & & 939 & 30.42 & 0.47 \\
\hline Camphene & & 954 & 5.29 & 0.31 \\
\hline$\beta$-Pinene & & 979 & 1.66 & 0.12 \\
\hline 3-Octanone & & 984 & 2.48 & - \\
\hline$\beta$-Myrcene & & 991 & 2.37 & 0.11 \\
\hline$\alpha$-Terpinene & & 1017 & 0.50 & - \\
\hline p-Cymene & & 1026 & 0.93 & 0.15 \\
\hline 1,8-Cineole & $\mathrm{C}_{1}$ & 1031 & 15.46 & 25.05 \\
\hline$\alpha$-Terpinene & & 1060 & 0.60 & - \\
\hline Terpinolene & & 1089 & 0.62 & 0.23 \\
\hline Linalool & $\mathrm{C}_{10} \mathrm{H}_{18} \mathrm{H}^{16} \mathrm{O}$ & 1097 & 2.08 & 1.67 \\
\hline Chrysanthenone & $\mathrm{C}_{10}^{10} \mathrm{H}_{14}^{18} \mathrm{O}$ & 1128 & 0.32 & - \\
\hline Unknown & & - & - & 0.15 \\
\hline Camphor & $\mathrm{C}_{10} \mathrm{H}_{16} \mathrm{O}$ & 1146 & 8.97 & 15.69 \\
\hline Pinocarvone & $\mathrm{C}_{10}^{10}$ & 1165 & 0.11 & - \\
\hline Borneol & $\mathrm{C}_{1}^{1}$ & 1169 & 7.16 & 9.15 \\
\hline Terpinen-4-ol & $\mathrm{C}_{1}$ & 1177 & 0.60 & 1.79 \\
\hline$\alpha$-Terpineol & $\mathrm{C}_{10}^{10} \mathrm{H}_{18}^{18} \mathrm{O}$ & 1189 & 1.72 & - \\
\hline Verbenone & $\mathrm{C}_{10}^{10} \mathrm{H}_{14}^{18} \mathrm{O}$ & 1205 & 13.09 & 5.17 \\
\hline Geraniol & $\mathrm{C}_{10}^{10} \mathrm{H}_{18}^{14} \mathrm{O}$ & 1253 & 0.55 & 1.32 \\
\hline Unknown & & - & - & 1.45 \\
\hline Unknown & - & - & - & 1.13 \\
\hline Bornyl acetate & $\mathrm{C}_{12} \mathrm{H}_{20} \mathrm{O}_{2}$ & 1289 & 2.07 & 1.29 \\
\hline Thymol & $\mathrm{C}_{10}^{12} \mathrm{H}$ & 1290 & - & 1.71 \\
\hline Carvacrol & $\mathrm{C}_{10}^{10} \mathrm{H}_{14}^{14} \mathrm{O}$ & 1299 & 0.21 & 2.07 \\
\hline Unknown & & - & - & 0.12 \\
\hline Piperitenone & $\mathrm{C}_{10} \mathrm{H}$ & 1343 & - & 1.85 \\
\hline$\alpha$-Copaene & & 1377 & 0.10 & - \\
\hline Geranyl acetate & $\mathrm{C}_{12}$ & 1381 & 0.11 & 2.49 \\
\hline$\beta$ - Caryophyllene & $\mathrm{C}_{15} \mathrm{H}_{24}$ & 1419 & 0.36 & 6.85 \\
\hline$\alpha$-Humulene & $\mathrm{C}_{15}^{15} \mathrm{H}_{24}^{24}$ & 1455 & 0.12 & 3.49 \\
\hline Germacrene D & $\mathrm{C}_{15}^{15} \mathrm{H}_{24}^{24}$ & 1485 & 0.10 & - \\
\hline$\beta$-Selinene & $\mathrm{C}_{15}^{15} \mathrm{H}_{24}^{24}$ & 1490 & - & 1.86 \\
\hline Valencene & $\mathrm{C}_{15}^{15} \mathrm{H}_{24}^{24}$ & 1496 & - & 0.81 \\
\hline$\beta$-Bisabolene & $\mathrm{C}_{15}^{15} \mathrm{H}_{24}^{24}$ & 1506 & 0.11 & 1.35 \\
\hline$\delta$-Cadinene & $\mathrm{C}_{15}^{15} \mathrm{H}_{24}^{24}$ & 1523 & 0.40 & - \\
\hline Caryophyllene oxide & $\mathrm{C}_{15} \mathrm{H}_{24}^{24} \mathrm{O}$ & 1583 & 1.40 & 2.87 \\
\hline Globulol & $\mathrm{C}_{15}^{15} \mathrm{H}_{26}^{24} \mathrm{O}$ & 1585 & - & 1.71 \\
\hline $\begin{array}{l}\text { Caryophylla-4 (12), } 8 \text { (13) } \\
\text {-dien-5- } \beta \text {-ol }\end{array}$ & $\mathrm{C}_{15}^{15} \mathrm{H}_{24}^{26} \mathrm{O}$ & 1641 & - & 2.17 \\
\hline Unknown & - & - & - & 1.67 \\
\hline Grouped components & & & & \\
\hline
\end{tabular}

Table 1. continued 


\begin{tabular}{|c|c|c|c|c|}
\hline Compounds & Formula & $\mathbf{R} \mathbf{I}$ & $\mathrm{HD}(\%)$ & SFE(\%) \\
\hline Hydrocarbon compounds & & & 43.58 & 15.75 \\
\hline Oxygenated compounds & & & 56.33 & 76.00 \\
\hline Monoterpene hydrocarbons & & & 42.39 & 1.39 \\
\hline Oxygenated monoterpenes & & & 50.27 & 65.47 \\
\hline Sesquiterpene hydrocarbons & & & 1.19 & 14.36 \\
\hline Oxygenated sesquiterpenes & & & 1.40 & 6.75 \\
\hline Others & & & 4.66 & 3.78 \\
\hline Total identified (\%) & & & 99.91 & 91.75 \\
\hline Extraction time (min) & & & 240 & 35 \\
\hline Oil yield (ml /100 g dry wt.) & & & 1.14 & 0.75 \\
\hline
\end{tabular}

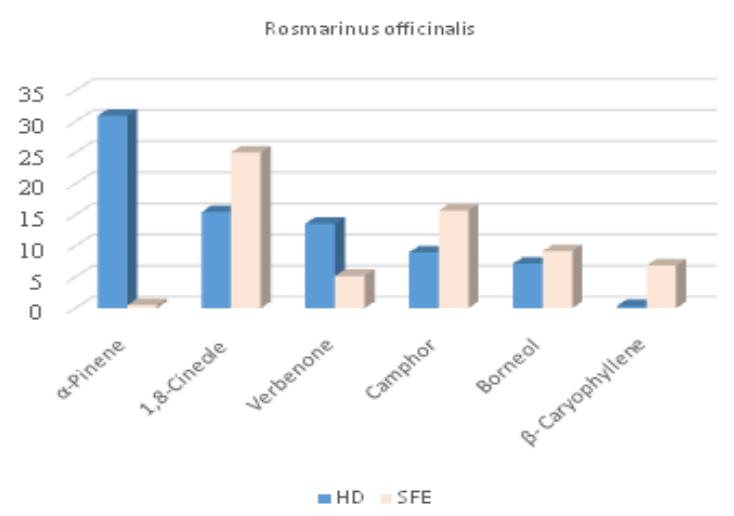

Fig. 1. Comparison the major compounds in Rosmarinus officinalis L.essential oil extracted via hydrodistillation (HD) and supercritical fluid extraction (SFE).

\section{CONCLUSION}

The supercritical fluidextraction of Rosmarinu sofficinalis $L$. was investigated, and the results, were compared with essential oil composition obtained via hydrodistillation. The SFE technique suggests well-known advantages over hydrodistillation. SFE needs shorter extraction times and less energy consumption. The possibility of influencing the composition of the oil, by altering the parameters of the extraction (pressure, temperature, modifier volume and dynamic extraction time) is more manageable in SFE. We

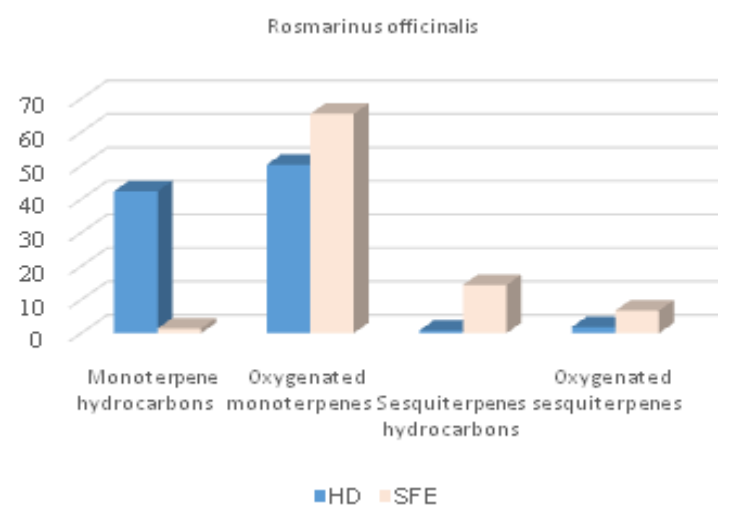

Fig. 2. Comparison hydrocarbon compounds and oxygenated compounds of essential oil extracted via hydrodistillation and supercritical fluid extraction

obtained a higher selectivity in SFE than by the subsequent hydrodistillation technique. Besides, the use of polar co-solvent is not necessary and the subsequent processing for solvent elimination is not required.

\section{ACKNOWLEDGEMENTS}

The authors are grateful to Dr. Mozaffarian Institute of Forests and Rangelands for identifying of plant material. This research was supported by the Islamic Azad University, Science and Research Branch.

\section{REFERENCES}

1. Bousbia, N.; Vian, M.A.; Ferhat, M.A.; Petitcolas, E.; Meklati, B. Y.; Chemat, F. Food Chem. 2009, 114, 355-362.

2. Jacotet-Navarro, M.; Rombaut, N.; FabianoTixier, A.S.; Danguien, M.; Bily, A.; Chemat, F. Ultrason. Sonochem. 2015,27, 102-105.
3. Jarrar, N.; Abu-Hijleh, A.; Adwan, K. Asian Pac. J. Trop. Med. 2010,3,121-123.

4. Okoh, O.O.; Sadimenko, A.P.; Afolayan, A.J. Food Chem. 2010, 120, 308-312.

5. Wang, W.;Wu, N.; Zu, Y.G.; Fu, Y.J. Food Chem. 2008, 108, 1019-1022. 
6. González-Vallinas, M.;Molina, S.;Vicente, G.Pharmacol. Res. 2013, 72, 61-68.

7. Hernández, M.D.; Sotomayor, J.A.; Hernández, Á.; Jordán, M.J. Chapter 77 Rosemary (Rosmarinus officinalis L.) Oils," in Essential Oils in Food Preservation, Flavor and Safety. 2016, 677-688.

8. Lemos, M.F.;Lemos, M.F.; Pacheco, H.P.; Endringer, D.C.; Scherer, R. Ind. Crops Prod. 2015, 70, 41-47.

9. Li, G.; Cervelli, C.; Ruffoni, B.; Shachter, A.; Dudai, N. Ind. Crops Prod. 2016, 84, 381390.
10. Fornari, T.; Vicente, G.; Vázquez, E.; GarcíaRisco, M. R.; Reglero, G. J. Chromatogr. A. 2012, 1250, 34-48.

11. Zabot, G. L.; Meireles, M. A. A.J. Supercrit. Fluids. 2014, 94, 234-244.

12. R. P. Adams, R. P. Identification of essential oil components by gas chromatography/ mass spectrometry, no. Ed. 4. Allured publishing co. 2007.

13. Carvalho Jr.,R. N.; Moura, L. S.; Rosa, P.T.V.; M. A. A. Meireles, M. A. A. J. Supercrit. Fluids. 2005, 35, 197-204. 